\title{
Glucose-6-phosphatase activity of endoplasmic reticulum and Golgi apparatus in spermatocytes and spermatids of the rat: an electron microscopic cytochemical study
}

\author{
Gro Thorne-Tjomsland ${ }^{\text {, }}$ Yves Clermont ${ }^{1 *}$, Xueming Tang ${ }^{2}$ \\ 'Department of Anatomy, McGill University, 3640 University Street, Montreal, Quebec, Canada H3A $2 B 2$ \\ ${ }_{2}^{2}$ Shanghai Second Medical University, Shanghai, China
}

(Received 16 August 1990; accepted 9 January 1991)

\begin{abstract}
Summary - The glucose-6-phosphatase (G6Pase) activity of cytoplasmic components of spermatocytes and spermatids of the rat was examined by electron microscope cytochemistry using cerium chloride as a capture agent. G6Pase activity, a recognized ERresident enzyme, was present in all ER cisternae of spermatocytes. In spermatids, while some ER cisternae were G6Pase-reactive, others were negative or only slightly reactive, indicating an unequal distribution of the enzymatic activity throughout the network of ER cisternae in these cells. In spermatocytes, the cis - and trans-elements of the stacks of Golgi saccules were slightly but significantly reactive for G6Pase. In the Golgi apparatus of spermatids, the cis-element, 4 or 5 underlying saccules, as well as one or two thick trans Golgi elements were G6Pase reactive. The G6Pase activity of the various Golgi elements, like that of the ER cisternae was not affected by the pH of the medium and was completely inhibited by Na-vanadate, a known G6Pase inhibitor. Sertoli and Leydig cells, submitted to the same cytochemical conditions, showed complete G6Pase reactivity of their ER; however in Sertoli cells, all Golgi components were consistently negative while in Leydig cells the cis - and trans-elements of the Golgi stacks were slightly reactive, as in spermatocytes. Thus, the G6Pase reactivity of Golgi elements, appeared variable from one cell type to another. The compact juxtanuclear Golgi apparatuses of spermatocyte- and spermatids were both associated with numerous G6Pase reactive ER cisternae; some were present at their surface, others crossed their cortices between Golgi stacks and formed elaborate networks in their cores. Other ER cisternae, in tur I. were closely apposed to or intertwined with trans-elements of the Golgi stacks, a relationship raising the possibility of molecular exusanges at this pole of the stacks in germinal cells.
\end{abstract}

glucose-6-phosphatase / endoplasmic reticulum / Golgi apparatus / spermatocytes / spermatids

\section{Introduction}

The topographical relationship of the endoplasmic reticulum (ER) with the cis face of the Golgi apparatus has been well documented by electron microscopists. Partly granulated ER cisternae, referred to as intermediate or transitional cisternae, located proximal to the Golgi apparatus usually display finger-like or bud-like projections directed toward the cis-element of the stacks of Golgi saccules. Clusters of small vesicles observed next to such ER protrusions are considered as carriers of partly glycosylated proteins from the ER to the Golgi saccules $[5,6,10,29]$. The relationship of ER cisternae with the trans-aspect of the Golgi stacks, although described in some cells [8, $11-13,30,31]$, has been given less attention. Novikoff et al $[27,28]$ have emphasized the close association of ER cisternae with secretory vesicles and lysosomes on the trans-aspect of the Golgi apparatus (GERL concept). Using electron microscope stereoscopic techniques Hermo et al [15] have demonstrated that in the Golgi apparatus of early spermatids, ER cisternae, although not in direct continuity with Golgi saccules, were closely applied to transGolgi elements and were also inserted between saccules on the trans-side of the stacks. A similar arrangement of ER cisternae with the trans-Golgi elements has recently been

* Correspondence and reprints observed in the epithelial cells of the proximal segment of the epididymis [16].

To further analyse the morphological relationship of ER cisternae with the various elements of the Golgi apparatus, a recognized ER-resident enzyme, glucose-6-phosphatase (G6Pase) $[9,24,25,40]$, was utilized as a cytochemical marker $[19,40]$ using cerium as a capture agent of the reaction product $[32,33]$. This cytochemical method applied to the spermatocytes and spermatids of the rat revealed a marked difference in the distribution of G6Pase between these two classes of germinal cells but emphasized the close association of ER cisternae with Golgi elements. Furthermore, some components of the Golgi apparatus of early spermatids showed a G6Pase reactivity which appeared significant as indicated by the various control experiments conducted.

\section{Materials and methods}

\section{Normal morphology}

Adult male Sherman rats $(300-400 \mathrm{~g})$ were anesthetized with intraperitoneal injections of pentobarbital and perfused retrogradely through the abdominal aorta with cacodylate-buffered $2 \%$ glutaraldehyde (pH 7.4). The testes were excised, the tunica albuginea and adnexae removed, and the testicular tissues cut into $1 \times 1 \times 4 \mathrm{~mm}$ pieces. These tissues were washed at $4^{\circ} \mathrm{C}$ in 0.1 $M$ sodium cacodylate buffer ( $\mathrm{pH} 7.4$ ) with 3 changes over a period of $20 \mathrm{~h}$. Subsequently, the tissues were postfixed at $4^{\circ} \mathrm{C}$ for $1 \mathrm{~h}$ 
in a $1 / 1$ mixture of $2 \% \mathrm{OsO}_{4}$ and $3 \%$ aqueous ferrocyanide [21], dehydrated in ethanols, and embedded in Epon 812. Thin sections $(60-80 \mathrm{~nm})$ were counterstained with uranyl acetate (5 min) and isad citrate $(2 \mathrm{~min}$ ) and viewed with a Philips 400 or $400 \mathrm{~T}$ transmission electron microscope. Step 7 spermatids and mid-pachytene spermatocytes were selected for the present study.

\section{Enzyme cytochemistry}

Tissues were collected, prefixed and washed as for standard electron microscope analysis with 2 modifications: $2.5 \%$ dextran and $4 \%$ sucrose were added respectively to the fixative and the washing buffer. Subsequent to the cacodylate buffer wash which followed fixation, the tissues were embedded in 4-7\% agar and cut at $35-50 \mu \mathrm{m}$ on a Sorvall tissue-chopper. The tissue sections were then rinsed consecutively in $0.1 \mathrm{M}$ sodium cacodylate buffers with 4\% sucrose of pH 7.4 and pH 6.5 and incubated on a shaking water bath for $1 \mathrm{~h}$ at $37^{\circ} \mathrm{C}$ in medium containing: $1 \mathrm{mM}$ glucose-6-phosphate, $2 \mathrm{mM}$ cerium chloride, $0.1 \mathrm{M}$ sodium cacodylate buffer (pH 6.5) and 8\% sucrose modified from Robinson and Karnovsky [33]; Robinson, [32]). Control sections were incubated in the above medium 1) without the glucose-6phosphate substrate, 2) with mannose-6-phosphate substituting for glucose-6-phosphate as a substrate, 3) with lead nitrate substituting for cerium chloride as a capture agent, 4) with the addition of 50,100 or $200 \mu \mathrm{M}$ sodium vanadate and, 5) over a range of $\mathrm{pH}$ between 5.0 and 7.5 , at 0.5 intervals. Following incubation, all tissues were rinsed 3 times for $45 \mathrm{~min}$ in $0.1 \mathrm{M}$ sodium cacodylate buffer with $: \% \%$ sucrose in the $\mathrm{pH}$ of their respective incubation media, then 3 times in the same buffer at pH 7.4. The tissues were then postfixed in ferrocyanide-reduced $\mathrm{OsO}_{4}$, dehydrated in ethanol, and embedded in Epon 812. Thin sections $(60-80 \mathrm{~nm})$ were counterstained with lead citrate $(2 \mathrm{~min})$ for viewing in a Philips 400 or $400 \mathrm{~T}$ microscope.

\section{Results}

\section{Spermatocytes}

In standard material postfixed with reduced osmium and stained with uranyl acetate and lead citrate, the Golgi apparatus of pachytene spermatocytes appeared as a well demarcated juxtanuclear spheroidal mass (fig 1). It was composed of a number of stacks of saccules disposed peripherally in the Golgi sphere. The convex faces of these stacks were usually oriented toward the surrounding cytoplasm. A smaller number of stacks, located in the core of the organelle, were disposed at random (fig 1). The saccules of the stacks were continuous with numerous membranous tubules between which many small spherical vesicles were observed (fig 1). Membranous profiles of various types were seen between the Golgi stacks. Some belong to a network of ER cisternae, but cannot be readily distinguished from Golgi elements. However, ER cisternae can be identified at the periphery of the Golgi apparatus and throughout the cytoplasm where they formed a broad network of interconnected nodular cisternae (fig 1).

\section{G6Pase activity in spermatocytes}

All profiles of ER cisternae were reactive with the glucose-6-phosphate substrate (fig 2). Some reactive cisternae were closely apposed to the surface of the Golgi apparatus (fig 3). Branches of these ER cisternae were seen traversing the cortical region of the Golgi apparatus between the stacks of saccules and forming an elaborate netwo: $k$ in the core of the organelle (figs 3,4$)$. Some of these ER cisternae were closely apposed to or intertwined with the slightly dilated trans elements of the Golgi stacks which usually showed a "peeling off"' configuration (figs 2-4). However, ER cisternae were never continuous with Golgi elements. While the various saccules of the stacks, the associated membranous tubules and the small vesicles seen throughout the Golgi region were unreactive for G6Pase, the cis elements and the trans Golgi elements often showed a weak but distinct G6Pase reactivity (figs 3,4 ) when compared to the various controls.

\section{Spermatids}

The ER of early round spermatids appeared as a number of circular or elongated membranous profiles which were aligned along the plasma membrane, distributed throughout the cytoplasm or closely applied to the surface of the Golgi apparatus. Its tri-dimensional configuration has already been documented $[2,15]$. The compact spherical or hemispherical Golgi apparatus of early spermatids which has already been extensively described in the past $[3,34$, $35,37-39$ ], showed a cortex composed of a number of stacks of saccules interconnected by membranous tubules (fig 5). The medulla contained a number of membranous profiles, some of which belong to the network of ER cisternae. Some of these ER cisternae, containing a wispy material, are closely applied to and/or sandwiched between trans Golgi elements (fig 5).

\section{G5Pase activity in spermatids}

In round spermatids, numerous profiles of ER cisternae were G6Pase reactive (figs 6, 8). Upon closer examination and in contrast to spermatocytes, some ER cisternae were either negative or reacted weakly with the G6Pase substrate (figs 6, 8). Nevertheless, all ER profiles in close association with the Golgi apparatus in the cortex and medulla were all heavily impregnated with ceriun ${ }_{i}$ (figs 6,7 ).

In addition, a number of elements forming the Golgi stacks were also G6Pase positive (figs 6,7 ). The cis element, which appeared as a series of interconnected elongated profiles, and the underlying 4 or 5 saccules showed a moderate but distinct labeling with cerium (fig 7). One or two flattened saccules on the trans side of the stacks, corresponding to the thiamine pyrophosphatase (TPPase) positive saccules [4] were unreactive with the glucose-6phosphate substrate (fig 7). Lastly, one or occasionally two thicker trans sacculotubular elements were strongly positive for G6Pase (fig 7). The latter corresponded to the cytidine monophosphatase (CMPase) positive trans Golgi elements $[4,39]$. The G6Pase positive ER cisternae seen on the trans side of the stacks were often inserted between the G6Pase unreactive saccules and the thick G6Pase reactive trans sacculotubular element (fig 7). The small vesicles seen throughout the cortex and medulla of the Golgi apparatus were G6Pase negative (fig 7). In the medulla, most larger membranous profiles were also unreactive except the previously mentioned ER cisternae and some large vesicles (figs 6,7 ) which are believed to form by fragmentation of the G6Pase positive trans Golgi elements [39].

\section{Controls}

\section{Substrate controls}

No reaction was present in sections which had been incubated in media which did not contain the G6Pase substrate. Substituting mannose-6-phosphate for glucose6-phosphate as a substrate resulted in staining of ER cis- 

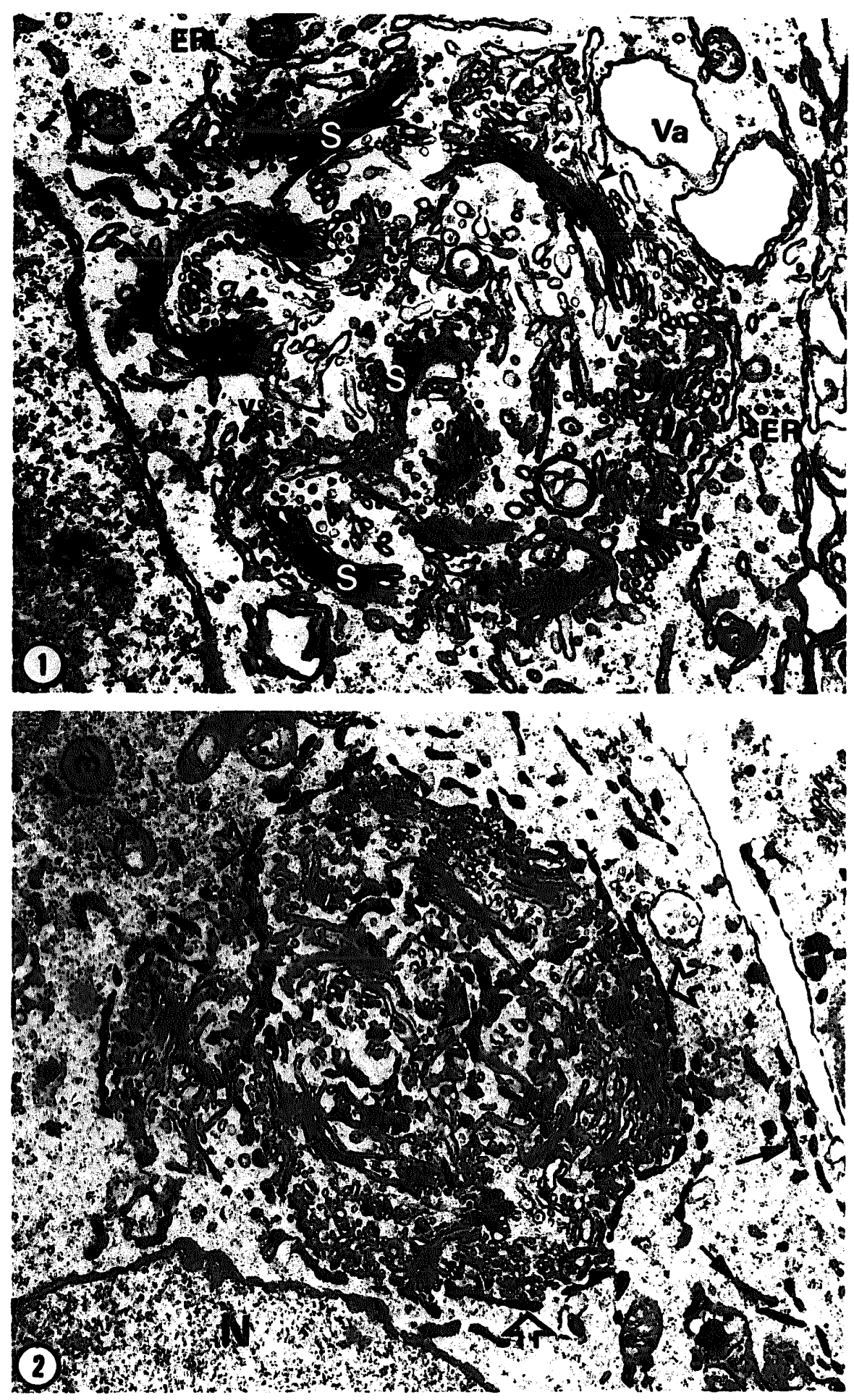

Fig 1. Section through the juxtanuclear spheroidal Golgi apparatus of a mid-pachytene spermatocyte. The Golgi apparatus comprises several stacks of saccules (S), some located at the periphery, others are seen in the core. The saccules of the stacks are continuous with membranous tubules (arrowheads). Numerous small vesicles (V) are seen throughout the organelle. ER cisternae (ER) are seen at the periphery of the Golgi region. ER cisternae are also present within the Golgi region but in the present section stained with uranyl acetate and lead citrate, they cannot readily be distinguished from the various Golgi elements. $N$, nucleus; Va, vacuole. $\times 20000$.

Fig 2. Golgi region of a pachytene spermatocyte stained to show G6Pase activity. The ER cisternae in the cytoplasm surrounding the Golgi apparatus are all G6Pase reactive (arrows). ER cisternae are also seen at the surface and within the Golgi region (empty arrows). Except for some reactivity within a few Golgi elements to be seen at higher magnifications in figures 3 and 4 , all other components of the Golgi apparatus, ie saccules, associated membranous tubules and vesicles are unreactive with the glucose-6-phosphatase substrate. $\mathrm{N}$, nucleus; $\mathrm{m}$, mitochondria. $\times 20000$. 

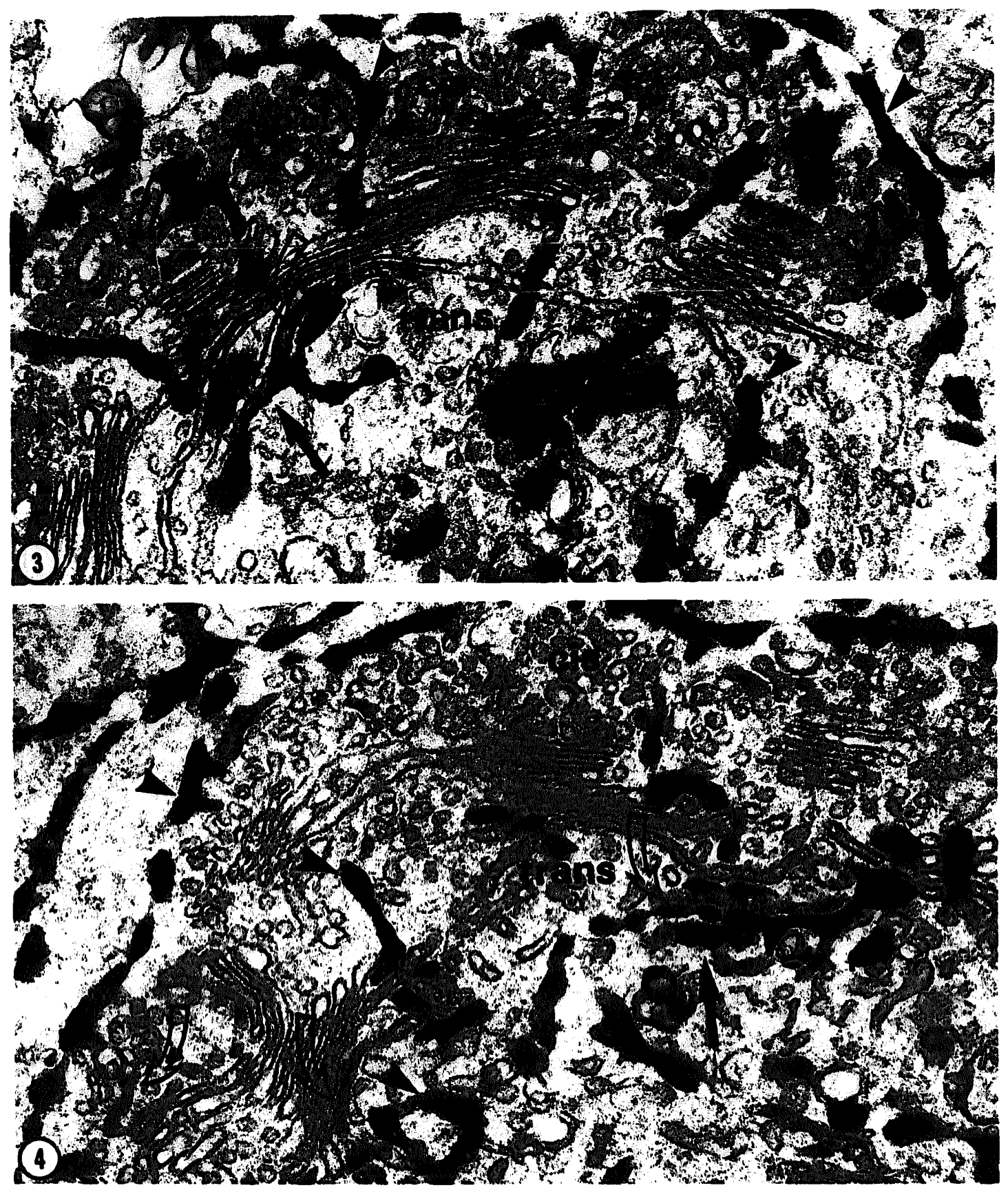

Figs 3 and 4. Two photographs each showing a small portion of the Golgi apparatus of spermatocytes stained to show G6Pase activity. The cis (cis) and trans (trans) sides of the stacks of saccules are indicated. G6Pase reactive ER cisternae are seen applied to the surface of the Golgi apparatus traversing the cortex of the organelle and forming an elaborate network in the core of the organelle (arrowheads). On the trans side of the stacks these cisternae are intertwined with trans Golgi elements (straight black arrows). The various Golgi elements (saccules, tubules or vesicles) are negative except for some cis- or trans-elements of the Golgi stacks which show a weak but distinct G6Pase reactivity (curved empty arrows). $\times 62000$.

Fig 5. Golgi region of an early spermatid (step 6) showing interconnected stacks of saccules (S) and numerous small vesicle forming the cortex of the organelle. In the medulla (M) several larger vesicular profiles are visible. ER cisternae (ER) are seen at the periphery of the Golgi apparatus but they are also inserted between saccules and applied to the trans elements of the stacks. A, acrosomic system; $N$, nucleus. $\times 36000$.

Fig 6. Small portion of a spermatid stained to show G6Pase activity. The sections pass through the hemispherical Golgi apparatus which is applied to the nucleus (N). In the cytoplasm some ER profiles are G6Pase reactive (arrowheads) in particular those which are applied to the surface of the Golgi apparatus, while others are unreactive (small empty arrows). Some ER cisternae are also seen within the Golgi region (white arrows). Some Golgi elements are also G6Pase reactive but this will be seen better at higher magnification in figure $7 . \mathrm{A}$, acrosomic system. $\times 17000$. 

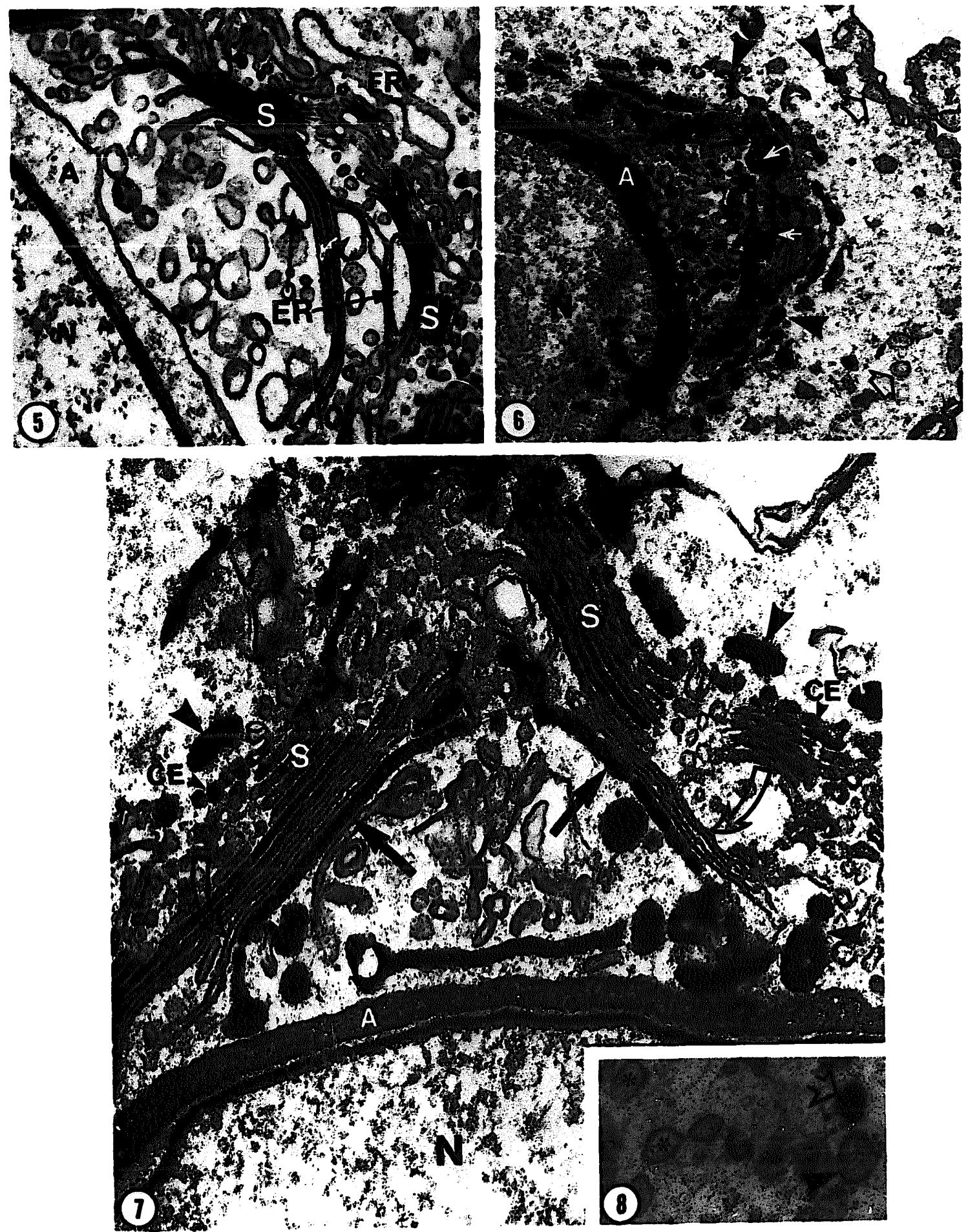

Fig 7. The juxtanuclear Golgi apparatus of an early spermatid (step 7) stained to show G6Pase activity. While some strongly reactive G6Pase reactive ER cisternae are identified (arrowheads), some Golgi elements are also reactive. Thus the cis-element (CE) and the underlying 4 or 5 saccules (S) show some reactivity. On the tranis-side of the stack one or two saccules are non-reactive (curved empty arrows). On the trans-side of the stacks some thick trans Golgi elements and associated buds are strongly reactive (straight black arrows). Other vesicular elements are unreactive. The nuclear envelope underlying the acrosomic system (A) is also G6Pase reactive. $N$, nucleus. $\times 65000$.

Fig 8. Small portion of the cytoplasm of a step 7 spermatid showing ER cisternae, some showing a strong G6Pase reactivity (empty arrow), a light reaction (arrowheads) or no reaction (asterisks). $\times 55000$. 
ternae and Golgi components of spermatocytes and spermatids which was indistinguishable from that observed in sections showing G6Pase activity.

\section{pir controls}

The G6Pase reaction was not affected by variations in $\mathrm{pH}$; at every $\mathrm{pH}$ tested between $\mathbf{5 . 0}$ and $\mathbf{7 . 5}$ the cerium salt deposits were consistently distributed as described through the ER and Golgi elements of both types of cells.

\section{Capture agent controls}

When lead nitrate was used as a capture agent instead of cerium chloride, the ER cisternae of both spermatocytes and spermatids showed a spotty lead deposit (figs 9, 10). Similar lead deposits were also observed over the Golgi apparatus (figs 9, 10).

\section{Enzyme inhibitor}

The addition of 50,100 or $200 \mu \mathrm{M}$ of the G6Pase inhibitor, Na-vanadate [36], to the incubation medium usually completely inhibited the G6Pase reactivity of the ER and Golgi apparatus of spermatocytes and spermatids (figs 11, 12). In the few cases where some reactivity remained, a lighter metal precipitate was present in both ER cisternae and some Golgi elements.

\section{Cell controls}

Two cell types ie Sertoli cells and Leydig cells present at proximity of germinal cells in the same agar-embedded sections, and thus exposed to exactly the same cytochemical conditions, were examined for their G6Pase activity. In Sertoli cells all ER cisternae, including the nuclear envelope, were G6Pase reactive but none of the Golgi elements showed labeling with cerium (fig 13). In Leydig cells there was a G6Pase reactivity of all ER cisternae and of the cis and trans-Golgi elements (fig 14) in a manner identical to that observed in spermatocytes.

\section{Discussion}

Value of the cerium technique for the ultrastructural localization of G6Pase activity in testicular cells

The cytochemical detection of G6Pase has been used repeatedly as a marker of ER cisternae [19, 40, 41, 43]. Lead nitrate, traditionally used as a capture agent, gave erratic results when applied to the testis. Whenever observed, the lead phosphate precipitate was spotty over the ER and Golgi apparatus, and, in addition, a fine nonspecific lead deposit was observed over the nucleus and cytoplasm of the various testicular cells. The utilization of cerium chloride as a capture agent instead of lead nitrate, originally recommended by Veenhuis et al [42], and utilized by some investigators thereafter $[14,20,22,33]$, considerably improved the localization of G6Pase activity within testicular cells. Indeed, the consistency of the results obtained in several successive experiments, the uniformity of the distribution of the fine cerium precipitate over ER cisternae and some Golgi elements as well as the absence of non-specific dusty cerium deposits over the nucleus and cytoplasm of the testicular cell argued in favor of using cerium ions as capture agents. In addition, the consistency of the G6Pase activity in acidic, neutral or slightly alkaline media minimized the possibility raised by Tokunaga et al [41] that the reactivity observed in the Golgi apparatus may be due to acid phosphatases, which are known to be present in the Golgi apparatus of spermatids in particular $[4,38,39]$. Recent results obtained by Luo et al [22] on the ultrastructural localization of various phosphatases in cells of the pineal gland also tend to validate the use of the cerium technique in the cytochemical localization of phosphatases.

\section{G6Pase activity in ER and Golgi apparatus of spermato- cytes and spermatids}

\section{G6Pase activity in ER}

In spermatocytes, all ER cisternae displayed G6Pase activity similar to the ER reactivity observed in Leydig cells, Sertoli cells and other cell types [19, 22, 41]. In contrast, the ER of spermatids was not uniformly labeled with cerium since some of the ER cisternae distal to the Golgi apparatus were G6Pase-positive, while others were either slightly reactive or negative. All ER cisternae associated with the Golgi apparatus were, however, G6Pase positive. The variation in G6Pase reactivity of spermatids ER cisternae does not appear to be the result of an incomplete penetration of the vibratome sections by the substrate since in adjacent spermatocytes all ER profiles were labeled with cerium. Thus, there appears to be, in spermatids, an unequal distribution of the enzymatic activity along the network of ER cisternae which is continuous throughout the whole cell [2].

\section{G6Pase activity in the Golgi apparatus}

One of the unexpected features observed in the present study was the presence of a G6Pase reactivity in some Golgi elements of both spermatocytes and spermatids. These results differ from those reported by Yokoyama and Chang [43] who used lead nitrate as a capture agent on Chinese hamster spermatocytes and spermatids and found that the components of the Golgi apparatus were unreactive for G6Pase. In the present study, the G6Pase cytochemical reaction was pronounced in the Golgi apparatus of rat spermatids since several saccules were G6Pase reactive in addition to the cis and trans element. The latter elements were also reactive in the Golgi apparatus of spermatocytes. When this G6Pase reactivity of Golgi elements of germinal cells was compared to that of other testicular cells, it was noted that while the cis and trans elements of the Golgi stacks of the Leydig cells showed a reactivity comparable to that of spermatocytes, none of the Golgi elements of Sertoli cells displayed a G6Pase reac-

Fig 9. Mid-pachytene spermatocytes treated with a medium containing lead nitrate as a capture agent. A spotty reaction was observed over the nuclear envelope (NE) and over the ER cisternae associated with the Golgi apparatus or distal from it (arrowheads). The saccules of the Golgi stacks contain a spotty reaction product. $\mathrm{m}$, mitochondria. $\times 7000$.

Fig 10. Section of a step 7 spermatid treated to show G6Pase activity but using lead nitrate as a capture agent. A spotty deposit is seen over ER cisternae (arrowheads) as well as over the acrosomic system (A). The localization of the G6Pase reactivity in particular
in relation to the Golgi apparatus is unclear. N, nucleus. $\times 20000$. 

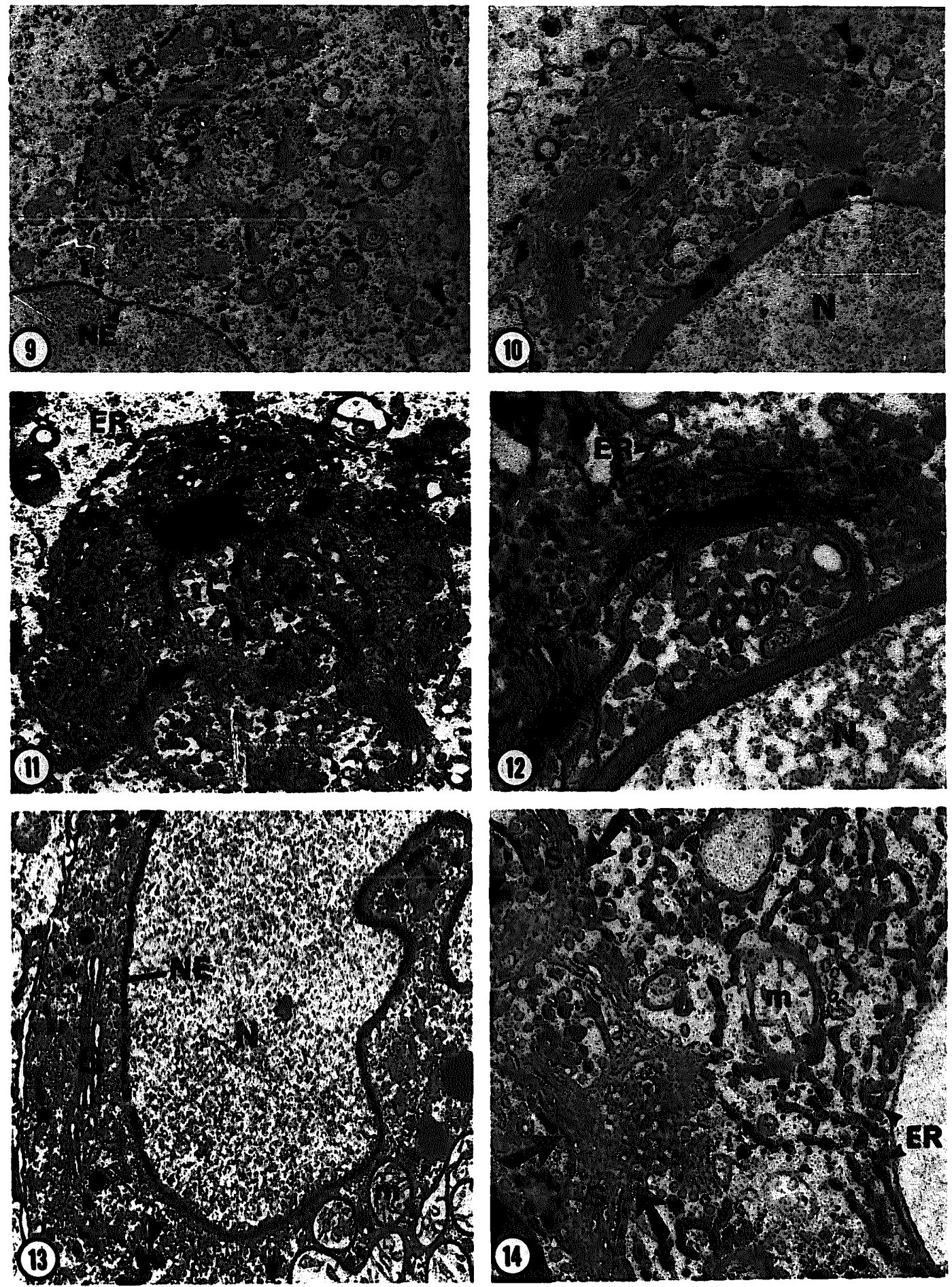

Figs 11-12. A mid pachytene spermatocyte (11) and a step 7 spermatid (12) treated with a G6Pase medium to which $100 \mu M$ sodium vanadate, a G6Pase inhibitor, was added to the medium. In both cell types the ER cisternae and elements of the Golgi apparatus were non-reactive for G6Pase. $\times$ 25000-80000.

Fig 13. Small portion of a Sertoli cell treated to show G6Pase reactivity. A cerium deposit is observed over the nuclear envelope (NE) and ER cisternae (arrowheads) but no G6Pase reactivity was noted over the elements of the Golgi apparatus (G). m, mitochondria. $\times 21000$.

Fig 14. Small portion of the cytoplasm of a Leydig cell treated to show G6Pase activity. A cerium deposit is present over the ER cisternae (ER); a light deposit is also seen over the cis and trans elements of the Golgi stacks (arrows). The other saccules of the stacks (S) are unreactive. $\mathrm{m}$, mitochondrion. $\times 20000$. 
tivity. It thus appears that the Golgi apparatus G6Pase activity may vary markedly from one cell type to another. The possibility that the Golgi apparatus reaction with the glucose-6-phosphate substrate is artefactual may not be retained, mainly because the testicular cells which were exposed to the same cytochemical conditions, thus serving as mutual controls, consistently showed a reaction which was characteristic for each cell type. Furthermore, the fact that G6Pase reactivity of both ER and Golgi apparatus was completely inhibited by Na-vanadate, a known inhibitor of G6Pase may also indicate that the G6Pase reaction is significant $[26,36]$.

In an early cytochemical study of Golgi fractions from rat liver, Farquhar et al [7] noted a G6Pase reaction in one of the fractions but assigned this result to a contamination with G6Pase positive ER cisternae. Howell et al [18], in a biochemical investigation observed that two enzymes, ie G6Pase and NADPH cytochrome $c$ reductase, thought to be restricted to the ER were present in freshly isolated liver Golgi fractions, and these authors raised the possibility that G6Pase may be a bona fide constituent of the Golgi apparatus. Our observations give credence to this possibility, but emphasize the fact that the Golgi-G6Pase reactivity may vary considerably from one cell type to another.

\section{Structural relationship or ER with the Golgi apparatus in spermatocytes and spermatids}

The present study with an ER cytochemical marker confirms the observations of a close topographical association of ER cisternae with the cis-face of the Golgi apparatus in germinal cells $[1,17,23,34,37]$ and other cell types $[5,6,10,29]$. The present study also confirms the close association of ER cisternae with the trans elements of the spermatid's Golgi apparatus as previously described by Hermo et al [15]. The association of ER cisternae with the Golgi apparatus of spermatocytes, described here for the first time, emphasizes the presence of ER cisternae in the core of the compact Golgi apparatus of these cells and underlines the close relation of ER cisternae with the trans elements of the Golgi stacks but the lack of continuity between these two membranous elements. Obviously more extensive than in the Golgi apparatus of Leydig cells and Sertoli cells there is a remarkably close association and interdigitation of ER cisternae with trans Golgi elements in germinal cells, a relationship also observed in the Golgi apparatus of some epididymal cells [16]. The reasons for such an extensive apposition of ER cisternae with the trans aspects of the Golgi stacks remain unknown, but this topographical relationship raises the possibility of molecular exchanges between ER and Golgi apparatus not only on the cis face of the Golgi stacks but also on the trans aspects of this organelle.

\section{Acknowledgments}

This work was supported by a grant from the Medical Research Council of Canada.

\section{References}

1 Burgos MH, Fawcett DW (1955) Differentiation of the spermatids in the cat (Felix domestica). J Biophys Biochem Cytol $1,287-300$
2 Clermont Y, Rambourg A (1978) Evolution of the endoplasmic reticulum during rat spermiogenesis. Am J Anat 151, 191-212

3 Clermont Y, Tang XM (1985) Glycoprotein synthesis in the Golgi apparatus of spermatids during spermiogenesis of the rat. Anat Rec 213, 33-43

4 Clermont Y, Lalli M, Rambourg A (1981) Ultrastructural localization of nicotinamide adenine dinucleotide phosphatase (NADPase), thiamine pyrophosphatase (TPPase) and cytidine monophosphatase (CMPase) in the Golgi apparatus of early spermatids of the rats. Anat Rec 201, 613-622

5 Farquhar MG (1985) Progress in unraveling pathways of Golgi traffic. Ann Rev Cell Biol 1, 447-488

6 Farquhar MG, Palade GE (1981) The Golgi apparatus (complex) - (1954-1981) - from artifact to center stage. J Cell Biol 91, 77s-103s

7 Farquhar MG, Bergeron JJM, Palade GE (1974) Cytochemistry of Golgi fractions prepared from rat liver. J Cell Biol 60, 8-25

8 Flickinger CJ (1969) Fenestrated cisternae in the Golgi apparatus of the epididymis. Anat $\operatorname{Rec} 163,39-54$

9 de Duve C, Berthet J, Hers HG, Dupret L (1949) Le système d'une glucose-6-phosphatase spécifique dans le foie. Bull Soc Chim Biol Paris 31, 1242-1253

10 Goldfischer S (1982) The internal reticular apparatus of Camillo Golgi: A complex, heterogeneous organelle, enriched in acid, neutral and alkaline phosphatase, and involved in glycosylation, secretion, membrane flow, lysosome formation and intracellular digestion. $J$ Histochem $C y$ tochem 30, 717-733

11 Hand AR (1980) Cytochemical differentiation of the Golgi apparatus from GERL. J Histochem Cytochem 28, 82-86

12 Hand AR, Oliver C (1977) Cytochemical studies of GERL and its role in secretory granule formation in exocrine cells. J Histochem 9, 375-392

13 Hand AR, Oliver C (1977) Relationship between the Golgi apparatus, GERL, and secretory granules in acinar cells of the rat exorbital lacrimal gland. J Cell Biol 74, 399-413

14 Hoefsmit M, Hulstaert CE, Kalicharan D, Eesterman IL (1986) Phosphatase cytochemistry with cerium as trapping agent. Histochemistry 24, 329-332

15 Hermo L, Clermont Y, Rambourg A (1979) Endoplasmic reticulum-Golgi apparatus relationships in early spermatids of the rat. Anat Rec 193, 243-256

16 Hermo L, Green H, Clermont Y (1991) Golgi apparatus of epithelial cells of the epididymal initial segment of the rat: Structure, relationship with endoplasmic reticulum and role in the formation of secretory vesicles. Anat Rec 229, 159-176

17 Hermo L, Rambourg A, Clermont Y (1980) Threedimensional architecture of the cortical region of the Golgi apparatus in rat spermatids. Am J Anat 157, 357-373

18 Howell KE, Ho A, Palade G (1978) Endoplasmic reticulum marker enzymes in Golgi fractions - what does this mean? J Cell Biol 79, 581-589

19 Hugon JS, Borgers M, Maestracci D (1970) Glucose-6phosphatase and thiamine pyrophosphatase activities in the jejunal epithelium of the mouse. J Histochem Cytochem 18 (5), 361-364

20 Hulstaert CE, Kalicharan D, Hardonk MJ (1983) Cytochemical demonstration of phosphatases in the rat liver by a cerium based method in combination with osmium tetroxide and potassium ferrocyanide postfixation. Histochemistry 78, $71-79$

21 Karnovsky MJ (1971) Use of ferrocyanide-reduced osmium tetroxide in electron microscopy. Proceedings of the 11th Meeting, Am Soc Cell Biol, New Orleans LA, Abstr 284, p 146

22 Luo Z, Schultz R, Whiter EF (1990) Ultrastructural localization of phosphatase activity in the guinea pig pineal gland by the cerium technique. J Histochem Cytochem 38, 793-801

23 Mollenhauer HH, Hass BS, Morré DJ (1976) Membrane transformations in Golgi apparatus of rat spermatids. A role for thick cisternae and two classes of coated vesicles in acrosome formation. J Microsc Biol Cell 27, 33-36 
24 Nordlie RC (1974) Metabolic regulation by multifunctional glucose-6-phosphatase. Curr Top Cell Reg 8, 33-117

25 Nordlie RC, Jorgenson RA (1976) Glucose-6-phosphatase. In: The Enzymes of Biological Membranes. vol, 2, (Martonosi AN, ed) Plenum Publishing Corporation, NY, 465-491

26 Nordlie RC, Sukalski KA (1985) Multifunctional glucose-6-phosphatase: A critical review. In: The Enzymes of Biological Membranes vol 2, (Martonosi AN, ed) Plenum Publishing Corporation, NY, pp, 349-398

27 Novikoff PM, Novikoff AB, Quintana A, Hauw JJ (1971) Golgi apparatus, GERL and lysosomes of neurons in rat dorsal root ganglia, studied by thick section and thin section cytochemistry. J Cell Biol 50, 859-886

28 Novikoff AB, Mori M, Quintana N, Yam A (1977) Studies of the secretory process in the mammalian exocrine pancreas. I. The condensing vacuoles. J Cell Biol 75, 148-165

29 Palade GE (1975) Intracellular aspects of the process of protein secretion. Science 189, 347-357

30 Rambourg A, Clermont Y, Hermo L (1979) Threedimensional architecture of the Golgi apparatus in Sertoli cells of the rat. Am J Anat 154, 455-476

31 Rambourg A, Clermont Y, Hermo L, Segretain D (1987a) Tridimensional architecture of the Golgi ap ratus and its components in mucous cells of Brunner's glands of the mouse. Am J Anat 179, 95-107

32 Robinson JM (1985) Improved localization of intracellular sites of phosphatases using cerium and cell permeabilization. $J$ Histochem Cytochem 33 (8), 749-754

33 Robinson JM, Karnovsky MJ (1983) Ultrastructural localization of several phosphatases with cerium. $J$ Histochem Cytochem 31, 1197-1208

34 Sandoz D (1970) Évo!stion des ultrastructures au cours de la formation de l'acrosome de spermatozoide chez la souris. J Microscopie 9, 535-558

35 Sandoz D, Roland JC (1976) Radioautographic study of glycoproteins and polyglycans. J Microsc Biol Cell 27, 207-214

36 Singh J, Nordlie RC, Jorgenson RA (1981) Vanadate: A potent inhibitor of multifunctional G-6-Pase. Biochim Biophys Acta 678, 477-482

37 Susi FR, Leblond CP, Clermont Y (1971) Changes in the Golgi apparatus during spermiogenesis in the rat. Am J Anat 130, 251-278

38 Tang XM, Lalli MF, Clermont Y (1982) Cytochemical study of the Golgi apparatus of the spermatid during spermiogenesis in the rat. Am J Anat 163, 283-294

39 Thorne-Tjomsland G, Clermont Y, Hermo L (1988) Con-ibution of the Golgi apparatus components to the formation of the acrosomic system and chromatoid body in rat spermatids. Anat Rec 221, 591-598

40 Tice L, Barrnett R (1962) The fine structural lacalization of glucose-6-phosphatase in rat liver. $J$ Histochem Cytochem $10,754-762$

41 Tokunaga H, Kanamuru S, Watanabe J, Kanai K, Sakaida M (1988) High glucose-6-phosphatase activity in osteoblasts in the metaphysis of femur of growing rats. Anat Rec 220, 252-257

42 Veenhuis M, Dijken JP van, Harder W (1980) A new method for the cytochemical demonstration of phosphatase activities in yeasts based on the use of cerous ions. FEMS Microbiol Lett 9, 285-291

43 Yokoyama M, Chang JP (1977) Cytochemical study of glucose-6-phosphatase in Chinese hamster testis. Biol Reprod 17, 265-268 